\title{
The challenge of widening citizen participation in climate change education: developing open educational resources on the lived experiences of climate change
}

\section{António Teixeira*, Paula Bacelar-Nicolau, Sandra Caeiro}

Universidade Aberta,

Rua da Escola Politécnica 141-147,

1269-001 Lisboa, Portugal

E-mail: amt@uab.pt

E-mail: pnicolau@uab.pt

E-mail: scaeiro@uab.pt

*Corresponding author

\section{Lieve Dams}

\section{KU Leuven,}

Oude Markt 13,

Bus 50053000 Leuven, Belgium

E-mail: lieve.Dams@dml.kuleuven.be

\section{Kees-Jan van Dorp \\ European Association of Distance Teaching Universities, Valkenburgerweg 177, 6419 AT Heerlen, Netherlands \\ E-mail: Kees-Jan.vanDorp@eadtu.eu}

\begin{abstract}
If climate change education is to become more than self-serving and contribute to meeting the global challenge of sustainable development, it must broaden its scope to include a wider range of students in terms of age, social group and ethnicity than is usually the case. In this paper the authors discuss how open and flexible learning can apply its strengths in the area of widening participation, as it can lever years of experience with non-traditional target groups. They show how flexible learning universities, such as Open Universities, may offer their curriculum as open educational resource (OER) for these types of learning and can indeed contribute for achieving such a needed critical mass. Mass education of this type may have a key role to play in meeting any global challenge, and climate change is no exception. In this paper, the authors exemplify it through an exploration of a partnership project between eight European universities in developing the LECH-e materials for a Master's curriculum on the lived experiences of climate change.
\end{abstract}

Keywords: climate change; sustainable development; SD; open educational resources; OER; e-learning; lifelong learning; LLL; widening participation. 
Reference to this paper should be made as follows: Teixeira, A., Bacelar-Nicolau, P., Caeiro, S., Dams, L. and van Dorp, K-j. (2012) 'The challenge of widening citizen participation in climate change education: developing open educational resources on the lived experiences of climate change', Int. J. Innovation and Sustainable Development, Vol. 6, No. 1, pp.66-77.

Biographical notes: António Teixeira is a Professor at the Department of Education and Distance Learning at the Portuguese Open University, a Researcher at the Centre for Philosophy at the University of Lisbon and a Vice-President of the European Distance and E-Learning Network.

Paula Bacelar-Nicolau is a Professor at the Department for Sciences and Technology at the Portuguese Open University (UAb), a Researcher at the Marine and Environmental Research Centre, Portugal and a Coordinator of the Master programme in Environmental Citizenship and Participation at UAb.

Sandra Caeiro is a Professor at the Department for Sciences and Technology at the Portuguese Open University (UAb), a Researcher at the Marine and Environmental Research Center, Portugal, and Coordinator of a BSc programme on Environmental Sciences and Institutional Coordinator of the European Virtual Seminar in Sustainable Development at UAb.

Lieve Dams is a Consultant for the Catholic University of Leuven.

Kees-jan van Dorp is a Research Director at the European Association of Distance Teaching Universities.

\section{E-learning for sustainable development}

One valuable outcome of the 1987 World Commission on Environment and Development was to define sustainable development (SD) to encompass the entire range of human values: "...development that meets the needs of the present without compromising the ability of future generations to meet their own needs". This definition recognises that SD is not just a trade-off between competing present-day values, or between material wealth and the well-being and respect for nature of a more intact ecosystem, but is also a temporal trade-off between short-term economic gains and long-term economic and environmental concerns (Ascher, 2007).

The United Nations Decade of Education for Sustainable Development (DESD, 2005-2014) aims to integrate the principles, values and practices of SD into all aspects of education and learning. Many educational institutions, universities in particular, are today actively striving to fulfil these aims into their activities at all levels of formal, informal and non-formal education. There is no doubt that universities can play a significant role in contributing to a more sustainable world by addressing sustainability through their major functions of education, research and outreach (Fadeeva and Mochizuki, 2010).

To educate citizens to be environmentally aware and active promoters of the principles, values and practices of SD is to educate them to become critical thinkers. This is because new ideas, policies, collective practices and individual lifestyles throughout 
the range (local to global) of interconnecting scales are essential if human beings are to understand fully and act upon complex problems such as climate change.

Critical thinking in relation to SD generally, and climate change particularly, combines two general attributes. Firstly, it offers the ability to assess the present in all of its tremendous economic, social, political and cultural implications.

Secondly, it provides the ability to create alternatives that meet both the needs of current generations equitably, and those of future generations. Even more important in terms of education, however, is to enable students to use their own, personal creativity, where education prepares them to act wisely as conscious human beings, as actors for change. Clearly, these are not just 'things of nature'. The wide-spread recognition obtained by SD in the previous decades lies with the fact that it affects all aspects of our lives. Enabling students to personalise their knowledge and awareness provides an internal impetus for change and creative thinking.

Creative thinking is therefore an important pedagogical strategy underpinning the aims and objectives of the lived experience of climate change (LECH-e) project. The idea is that students learn about climate change from their own lived experience of it, and to assimilate, within that lived experience, knowledge provided on the subject from the natural and social sciences. So, to enable students to understand the phenomena of SD is to train them to use their own creativity. In SD education, we believe that formalised frameworks for problem solving may be not so effective to help students to understand the issues as to focus on their personal interpretations. In this case, to understand is to re-invent. Thus, the emphasis is on the individual, the self (Runco, 2008). Sustainable development students are being educated to change the way their communities act and live and so be creators. As suggested by Simonton (1995), only creative people change the way that others think. Sustainable development education should be therefore flexible and learner-centred.

The e-learning system is essentially a teaching and learning process that allows flexible learner-centred education. Since it draws on a diverse information system based on the World Wide Web, it potentially provides an inter-disciplinary approach to teaching and learning which is a key facet of education for sustainable development and in our project is the basis of climate change education (Wilson et al., 2011).

If accessibility to the web is assured, it can be claimed e-learning is a system independent of time and place (Lee and Lee, 2008; Garrison, 2000). When compared to traditional face to face adult learning, it is claimed that e-learning can bring new dimensions and increases the motivation to learn about sustainability issues, allowing new ways of exploring and solving environmental problems in an interactive way. Moreover, it may increase the readiness to learn if students are allowed to move into new social roles through their study (Eneroth, 2000). Also, there is a direct benefit, where e-learning has the potential to reduce the environmental impacts that are found in face-to-face systems (Roy et al., 2008; Pérez, 2008). These include: potential resource savings in the use of time, space heating and ventilation, transportation, paper and generation of waste. Eneroth (2000) demonstrates that e-learning has high potential for ESD at all levels of the adult education process.

All of these advantages of e-learning can be claimed by the LECH-e project. Above all, however, the e-learning approach used in this project is designed to enable international virtual mobility of students. Further, specific activities in the curriculum workbooks are designed for group simulations which tap into this rich source of virtual mobility to deliver transboundary competence (Wilson et al., 2011; Salgado et al., 2011 
in this special issue). Given the highly contested nature of climate change such competence, defined as the ability to engage and work across deep differences in perspective and cultural boundaries, is considered essential both for sustainability in education and addressing climate change policy itself (see also Section 3 below).

In fact, students who study in this way are often adults with significant professional and other experience in the subject area. Moreover, many are currently employed in the subject or related areas and are studying part-time, using their jobs as the site of their 'fieldwork'. Currently around 30 students are engaged in the pilot delivery of the LECH-e project and are a rich mix indeed. They range from concerned individuals to activists to professionals in the private, public and NGO sectors, and to those who work for agencies such as the United Nations Framework Convention on Climate Change. They therefore bring to the virtual mobility space a rich and diverse mix of experiences which can only enhance their study through collective, critical reflection on the formal teaching materials that are provided by academics. This is truly democratising education and is a key feature of sustainability in education.

As stated above, educating Europeans and citizens world-wide to address such environmental topics as climate change cannot limit itself to provide a wider access to quality information and knowledge for all. Much more than that, SD education is a very complex process which basically is directed at empowering individuals to help communities to change and adjust themselves. It is therefore a cultural process in which students are being prepared to become social actors. They are expected to act in very diverse specific contexts and so must be prepared to find creative solutions to the problems faced. In this sense, the education process cannot be seen as a one-way communication, as dissemination of quality content to a wide audience of end-users. On the contrary, the educational process has to be not only culturally inclusive, but also interactive. Students themselves can contribute to introducing improvements and adjustments both in content and in the learning materials.

The development and implementation of an articulated strategy, making full use of open educational resource (OER) potential, is therefore of critical importance. OER can allow for continuous feedback and subsequent updating of content and improvement of materials. Additionally, it is also very important to note that the use of advanced e-learning in this open form helps to develop a more creative form of learning.

\section{OER widening participation: adoption and partner development}

Addressing the lifelong learner throughout different disciplines and domains can however be a challenging task as many higher education institutions in Europe are discovering. In fact, many universities are not sufficiently open to providing courses for students in later stages of life, and tend to offer the same courses to the same age groups. They fail to open up to other types of learning and learner groups. Of course, this has potential risks, namely the possible fall of enrolment rates in view of demographic change, a possible declining average level of education, and last but not least the long-term devaluation of a skilled labour force.

Open and flexible learning can apply its strengths in this area, as it can lever years of experience with non-traditional target groups. Flexible learning universities, such as open universities, may forward OER for these learners, and can make a strong contribution to 
the realisation of lifelong learning (LLL) potential. With a major focus on research in lifelong open and flexible learning, a critical mass and European coverage can be met, and a sustained pedagogically-rich content with distance facilities can be supported: such universities are able to create an internationally recognised brand for OER.

In this respect, OER has the strong potential to support the largely missing component in the European higher education system, namely support for widening participation and the inclusion of LLL for the learners aged over 25. In fact, in Europe today most of the population has good access to broadband internet and technology. Opposite to what still happens in poor areas of the world, the digital divide is no longer the issue of access to technology that it once was. Rather, the issue is of content.

The lack of appropriate content identified above, is particularly due to the often unclear institutional strategies of traditional universities, and still more important, the deficiency of sustainable OER models for LLL for these important target groups. Two particular aspects need to be taken into consideration for successfully widening participation, and are planned for the LECH-e project:

- increased accessibility of content for users, through self-learning models which are emerging as key elements in successful widening participation

- more rapid (re)production of content, facilitated by the new generation licences such as Creative Commons which stimulate the propagation and sharing of content.

Another important aspect in achieving effective, wider participation in SD education is localisation, that is the need to adapt content and materials to take into account of different cultural and linguistic contexts. In view of this, LECH-e OERs can be continuously enriched by the network of potential additional contributors within the community of users, both academics and students. Individual, but also community creativity is fostered in this sense by the use of resources that are open to use, reuse and redesign.

Within the LECH-e Consortium, OER is therefore designed to increase participation in LLL through providing open access for people of all ages, and is also easily accessible to those with special needs and disadvantaged groups, regardless of their socio-economic background. LECH-e OER thus particularly stimulates the adoption of pedagogical, technological, organisational frameworks for strategic implementation by individual institutions, as well as by collaborative international partnerships. Key for widening participation through the LECH-e project is that the starting point for each institution within the LECH-e Consortium, is to connect properly with its own development stage that is already in place. This might be on a continuum from awareness raising to strategy building to the design of pedagogical, technological, organisational models (Figure 1).

Flexible learning universities seem to be profiling themselves particularly as frontrunners in this area. Many of them are open universities, that have recently discussed internally new OER strategies and they are exploring with the support of external partners viable OER business models in the area. Innovative aspects are: self-learning pedagogy, ICT innovation, accessibility, sharing and reproduction of content. And, out of recent experience, it is learnt that the expertise of these frontrunners combined with the LECH-e project approach, can lead to an important impact in diffusion of OER in the domain of sustainable development, and for climate change particularly. Synergies are currently harvested in the LECH-e consortium between individual partners, as well as through dedicated products, which will lead to an increased multiplier effect. The span of 
diffusion of OER by the LECH-e consortium determines for a large part the acceptance of OER. Partners must cross different stages to have OER accepted by their own institution (Van Dorp and Lane, 2011). Diffusion of OER can be regarded as a process, an adoption process (Rogers, 1962, 1983, 1995, 2003). Such a process may take place through a series of communication channels over a period of time among members belonging to the same social system. In Roger's Diffusion of Innovations model (Rogers, 1962), five phases in the adoption process are distinguished: knowledge, persuasion, decision, implementation, and confirmation (Figure 2).

Figure 1 OER development stages (see online version for colours)

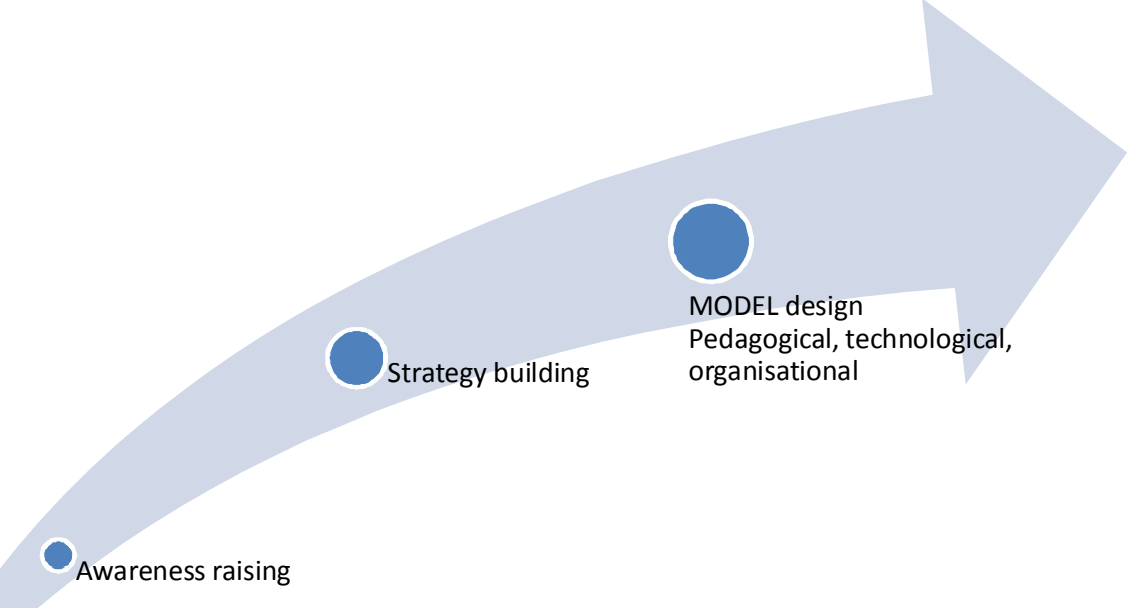

Figure 2 Five phases in the adoption of innovations

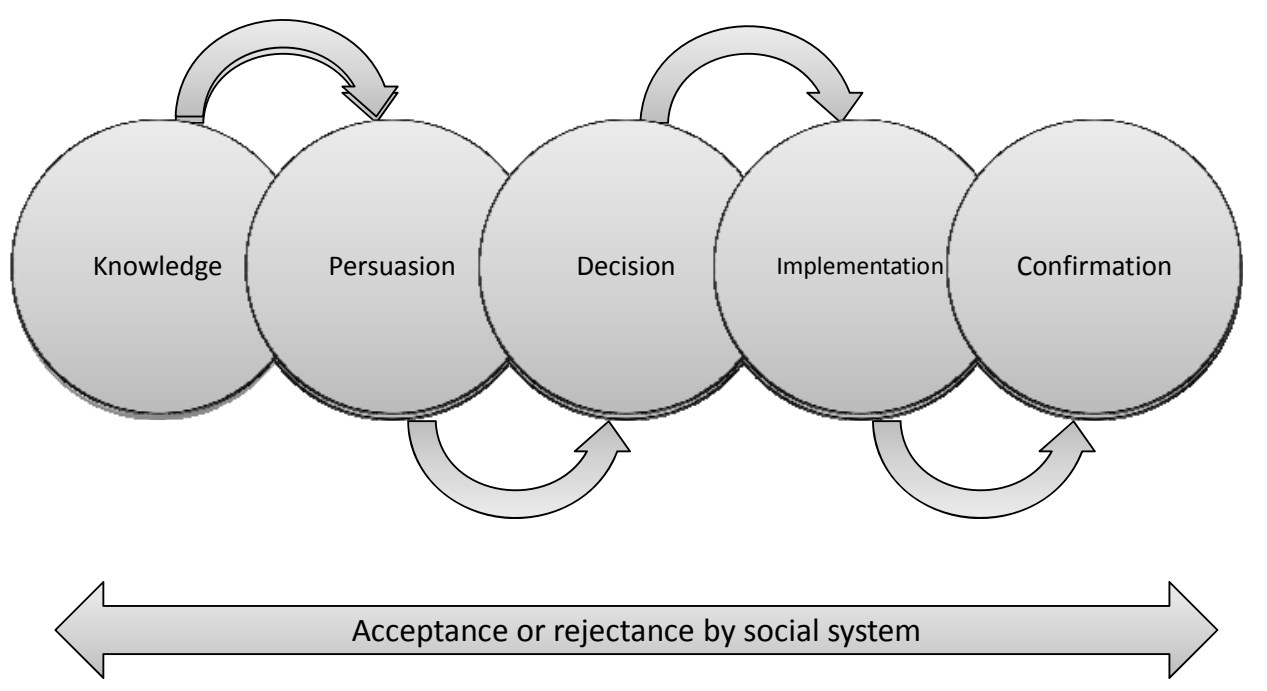


Source: Rogers (1962)

Let us now examine the mechanics of the five phases. In the knowledge phase, the individual (or institution) is first exposed to an innovation but lacks information about it. During this phase of the process the individual has not been inspired to find out more information about the innovation. In the persuasion phase, the individual (or institution) is interested in the innovation and actively seeks information/detail about it. In the decision phase, the individual takes the concept of the innovation and weighs the advantages/disadvantages of using the innovation and decides whether to adopt or reject it. Due to the more closed or less open nature of this phase Rogers notes that it is the most difficult stage to acquire empirical evidence. In the implementation phase, the individual (or institution) employs the innovation to a varying degree depending on the situation. During this phase the individual determines the usefulness of the innovation and may search for further information about it. In the confirmation phase, the individual (or institution) finalises their decision to continue using the innovation and may use the innovation to its fullest potential.

In addition to this model of adoption, any strategic success of partner institutions with respect to sustainable development as competence of the whole institution, depends strongly on the appropriate organisation of its collective ambition and the presence of core competences. For building and developing new core competences, collective learning is needed according to Hamel and Prahalad (1994). These authors relate the strategic intent of an organisation, that is to say the collective ambition, to the development of core competences and indicate that when an organisation is not yet successful in an area, but wants to move ahead, an investment is first of all made in strengthening the collective ambition, followed successively by the development of the necessary competences. Figure 3 depicts the relation between the collective OER ambition and the development of necessary OER competence.

Figure 3 The road to OER success through collective ambition and competence

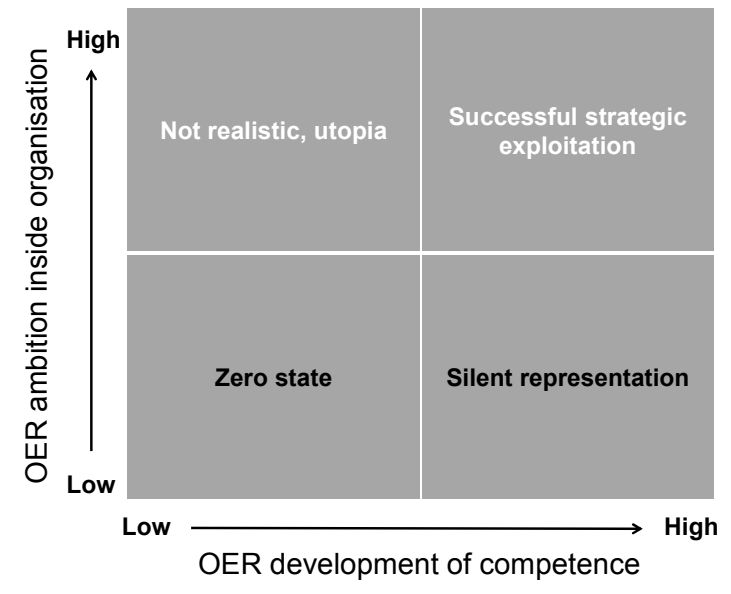

Source: Based on the framework of Hamel and Prahalad (1994)

Imagine an organisation commencing from a zero state, from which it moves to develop competence in OER. When it is able to develop OER competence among only a small quantum of learners (even if it is high competence), it will only manage what may be 
termed a 'silent representation'. The organisational leverage is rather insignificant and the strategic underpinning is negligible. An OER ambition can however be successfully underpinned if the development of OER competence is widely adopted by learners throughout an organisation. In the case of such a collective learning ambition, with a clear strategic intent, the organisation is likely to move from 'silent representation' towards 'successful strategic exploitation'. Organisations may also cherish very high level OER ambitions, while the 'actual' OER development of competence remains largely underdeveloped. In such situations, the collective learning ambition remains a rather utopian scenario, and as such, the organisation is out of touch with reality.

How are these stages of advancement related to the LECH-e consortium? We believe that the collective effort of diffusion and acceptance of OER for sustainable development by the LECH-e frontrunners (and followers) is about to make a big impact. The LECH-e project acts as a leverage. On the institutional level, many institutions within the LECH-consortium are already and simultaneously active in development of institutional OER competence for other educational disciplines. The development of OER for sustainable development will only contribute to strengthen and reinforce the collective ambition and competence development in institutions, hence reaching more easily a successful strategic exploitation for OER in general. In this respect the LECH-e project is one important contributor to success.

\section{Widening citizen participation in climate change education: how sustainable is the LECH-e e-learning project?}

Given its objectives and being a fixed-term and externally funded initiative, the sustainability of the results is a very significant challenge for the LECH-e project. In fact, the professional ethos of the team members means that they want the materials that they produce disseminated and exploited as widely and sustainably as possible. Just as climate change is a global challenge, so too is education at all levels in relation to it.

Following this, the project conducted an initial survey of its partners, out of which four strategic priorities were formulated. To develop:

1 e-learning learning modules that have content, level and scope required for accreditation and/or integration into existing/proposed postgraduate programmes

2 a sustainable virtual learning space (VLS)

3 a sustainable system for delivery, maintenance and regular updating of the teaching modules as OER

4 a sustainable system for maintenance and regular updating of the project's Masters dissertation package and the LECH-e research repository.

The next text is an account of the challenges of sustainable exploitation facing the LECH-e open e-learning project and how they are being addressed.

\subsection{E-learning learning materials that can be accredited}

The LECH-e curriculum resources are designed to complement and/or to be embedded into existing/proposed Masters programmes on climate change and related subjects 
organised by the participating universities. This will typically be done by accrediting institutions providing their own formal assessment and student support.

Although the credit systems of the participating universities differ, most refer to the European Credit Transfer and Accumulation System (ECTS). Therefore, and to give the sizes of the modules clear definition, it was agreed to set each module at 4-5 ECTS points after formal assessment has been added, corresponding to 100-120 hours of study.

The general design of the teaching modules is based on giving students maximum flexibility in their use. Because students will have academic backgrounds from a variety of disciplines which might be based in either the natural or social sciences, the LECH-e text-book model offers them the opportunity to study only the contents in which they are interested or with which they are not yet familiar. While all students are encouraged to do the exercises and self-assessments that are provided in the workbooks in order to enhance their study, it is possible that some may only choose to read the narratives of the textbooks. All students who are studying for credit, however, will be expected to group work activities that are described in the workbooks as part of the skill of developing transboundary competence (see Section 3.2 below) and their participation is assessed.

Formalisation of accreditation and hence tutoring is the responsibility of each partner institution, thus overcoming the difficulties associated with gaining joint accreditation across institutions. Some participating universities are already ready to accredit the modules and/or to integrate them into accredited programmes for master students. Over time accrediting institutions may also wish to adapt the modules for their particular curricula, and others update time passes (see Section 3.2 below). Another possibility is that universities do not accredit but their students use the modules as resources for their Masters study, just as they would use a reading list that is provided to them. Producing these modules ultimately as OER keeps all of these options open.

\subsection{The sustainable VLS}

The VLS is a key feature of the project. In particular it is the medium for guaranteeing virtual mobility within the project and developing the key skill of transboundary competence - as defined above in Section 1 (see Salgado et al., 2011, in this special issue). Sustaining the VLS beyond the project poses a particular challenge, but an essential one to meet as it will guarantee continuous mentoring and updating into the future.

The VLS accompanies the students during their academic studies and comprises two virtual learning communities. One is restricted to students studying the modules, their supervisors and other relevant academic staff. The second extends this concept to those who might be the objects of dissertation research (individuals, community groups, etc.) The pilot, running from March until November 2011, is very important for establishing the VLS.

Once established, the VLS cannot be a static space which is left unattended. To gain and maintain a critical mass of active, engaged users and to ensure the sustainability of the VLS, special care has been taken to establish synergy with the 'Virtual Campus for a Sustainable Europe' (VCSE). The VCSE is a platform that potentially surpasses the gates of academia. It makes it possible to invite a wider public of relevant academic, political and societal actors to a public dialogue about dealing with the complex issue of SD, and in our case, climate change (http://www2.leuphana.de/vcse). 


\subsection{A sustainable system for open educational practices}

The LECH-e project will promote the sharing and use of the produced e-learning materials beyond the project's end. To allow free use and modification in academic institutions and other organisations (in European and be registered under a creative commons licence.

For long-term sustainability it important to gather evidence of the impact of any OER through tracking of its use and versioning. It will be part of the LECH-e pilot to examine ways to capture and structure user commentaries on the material. Inviting users to update and adapt the OER is one way to keep open resources updated, and might be termed the 'Wikipedia' model. Another way is to promote accreditation so that institutional staff and resources will be committed to update the materials. We intend to use a creative commons licence which includes a 'share-alike' clause, so that materials updated or adapted by accrediting institutions will also be obliged to appear as OER. The two ways - the Wikipedia model and updating via accrediting institutions - are complementary.

To improve accessibility for formal and informal learners in European and other countries there is an agreement to provide the texts in different formats and file sizes to avoid problems for those with slow internet connections (which is often the case in many developing countries), and also examine possibilities of funding for translation from English later.

\subsection{A sustainable system for the Masters dissertation package and research repository}

The e-learning learning materials are designed to combine knowledge of the global mechanisms of climate change with local experiences of impacts. The promotion of the development and sharing of Masters theses on the topic of the 'LECH-e' is therefore a major issue. These Master theses themselves form an important dataset for:

- $\quad$ advocacy with policy makers on climate change

- further research into this under-studied aspect of climate change knowledge.

The LECH-e project envisages that Master theses can be written in the students' first language, accompanied by a summary in English.

Special care will be taken to search for synergy with the European Regional Centres of Expertise (RCE) networks and with other local bodies who work on climate change, and who are most likely to benefit from the knowledge produced. To invite them to suggest Master dissertation topics is one way to involve them at an early stage and to encourage them to become active stakeholders for external exploitation.

Once again, this is part of the strategic approach used in LECH-e to articulate the strategic use of OER with a learning process based on developing creativity and collaboration. In fact, the intended synergies with RCEs and other bodies is a way to empower local actors. It makes full use of the tremendous creative potential of these individuals as well as validates the reflection undertaken across these networks which are amazingly rich repositories of experience of sustainable development. By doing this, the universities in the LECH-e consortium are able to foster academic research based on new data and ideas. 


\section{Conclusions: the ongoing challenge of widening citizen participation in climate change education}

Distance learning and especially e-learning has acquired a new importance for universities. Moreover, open educational practices constitutes a most effective way to provide wide-spread, instant and constant access to quality learning opportunities. In this paper we tried to demonstrate how the use of OER makes possible for higher education institutions and individual students or researchers all over the world not only to access, but also to share high quality materials, thus increasing the standards of education for sustainable development. Moreover, as we tried to show, the new generation of OER opens a new and even more exciting possibility. In fact, today users can also change and adapt OER content, either updating it or adjusting it to new educational needs or different learning and cultural contexts. This possibility is absolutely critical for climate change education since rapid and constant updating of scientific data and information is of outmost importance for assuring the quality and proficiency of the learning process.

In this sense, we believe the use of new generation OER in education for sustainable development make it really possible to widen participation in the full meaning of the term, because, they allow for every user to become also a contributor and a co-producer. In fact, the wide spread use of OER in climate change education is not just a form of disseminating knowledge on the topic, but also of contributing to form a large and sustainable community of researchers, engaged in a constant process of content re-production. However, for this possibility to become an acceptable reality by the scientific community, it is critical that original 'producers' play also a role as co-evaluators, validating the changes made to the materials. If that is assured, we are able to build a true learning community through the wide-spread use of OER. By creating a community of users we are also starting a community of contributors to the common and shared production of knowledge.

In this paper we tried to demonstrate how the LECH-e approach to OER contributes therefore to a wider and more inclusive notion of education for sustainable development. This notion of education for sustainable development is much more socially sustainable because it manages to involve formal, informal and non-formal learners in the production, reproduction, dissemination and preservation of knowledge on climate change. Learners and academics are invited to use freely the resources in the most distinctly creative ways.

\section{Acknowledgements}

This research conducted under the LECH-e project was supported by the European Commission - Lifelong Learning Programme. We wish to thank the EC support. 


\section{References}

Ascher, W. (2007) 'Policy sciences contributions to analysis to promote sustainability', Sustainability Science, Vol. 2, No. 2, pp.141-149.

Van Dorp, C.A. and Lane, A. (2011) 'Diffusion and adoption of open educational resources', eLearning Papers, Vol. 23, Nos. 1887-1542, p.12.

Eneroth, C. (2000) 'E-learning for environment. Improving e-learning as a tool for cleaner production education', Licentiate Dissertation, Lund University.

Fadeeva, Z. and Mochizuki, Y. (2010) 'Higher education for today and tomorrow: university appraisal for diversity, innovation and change towards sustainable development', Sustainability Science, Vol. 5, No. 2, pp.249-256.

Garrison, R. (2000) 'Theoretical challenges for distance education in the 21 st century: a shift from structural to transactional issues', International Review of Research in Open and Distance Learning, Vol. 1, No. 1, pp.1-17.

Hamel, G. and Prahalad, C.K. (1994) Competing for the Future, Harvard Business School Press, Boston, MA.

Lee, J. and Lee, W. (2008) 'The relationship of e-learner's self-regulatory efficacy and perception of e-learning environmental quality', Computers in Human Behavior, Vol. 24, No. 1, pp.32-47.

Pérez, S. (2008) Online onderwijs en duurzaamheid: een groene inktvlek, School of Science, Open Universiteit Nederland.

Rogers, E.M. (1962) Diffusion of Innovations, Free Press, New York.

Rogers, E.M. (1983) Diffusion of Innovations, 3rd ed., Free Press, New York.

Rogers, E.M. (1995) Diffusion of Innovations, 4th ed., Free Press, New York.

Rogers, E.M. (2003) Diffusion of Innovations, 5th ed., Free Press, New York.

Roy, R., Potter, S. and Yarrow, K. (2008) 'Designing low carbon higher education systems. Environmental impacts of campus and distance learning systems', International Journal of Sustainability in Higher Education, Vol. 9, No. 2, pp.116-130.

Runco, M. (2008) 'Creative and education', New Horizons in Education, Vol. 56, No. 1, pp.96-104.

Salgado, P.F., Kraker, J., Boon, J. and van der Klink, M. (2011) 'Competences for climate change education in a virtual mobility setting', International Journal of Technology Enhanced Learning.

Simonton, D.K. (1995) 'Exceptional personal influence: an integrative paradigm', Creativity Research Journal, Vol. 8, No. 4, pp.371-376.

Wilson, G., Abbott, D., De Kraker, J., Pérez, S., Terwisscha van Scheltinga, C. and Willems, P. (2011) 'The lived experience of climate change: creating open educational resources and virtual mobility for an innovative, integrative and competence-based track at Masters level', International Journal of Technology Enhanced Learning, Vol. 3, No. 2, pp.111-123. 